\title{
Effects of Exercise Type on Neck Disability, Pain, and Postural Changes in Subjects with Forward Head Posture: Systematic Review and Meta-Analysis
}

\author{
Jeong-Gon Na, PT • Han-Suk Lee, PT, Ph. $\mathrm{D}^{1 \dagger} \cdot$ Sun-Wook Park, PT, Ph. $\mathrm{D}^{2}$ \\ Department of Physical Therapy, Graduate School of Eulji University \\ 'Department of Physical Therapy, Eulji University \\ ${ }^{2}$ Department of Physical Therapy, Samsung Medical Center
}

Received: June 13, 2018 / Revised: June 22, 2018 / Accepted: July 14, 2018

(C) 2018 J Korean Soc Phys Med

\section{| Abstract |}

PURPOSE: This study was conducted to investigate the effects of type of exercise on neck disability, pain, and postural changes in subjects with forward head posture.

METHODS: Two independent researchers conducted a search using KISS, RISS, DBpia (domestic), PubMed, OVID, and Science Direct (overseas) databases. We selected randomized controlled clinical trials by searching using the terms "forward head posture", "exercise therapy", and "therapeutic exercise". Studies published from 2007 to December 2017 were included. PEDro Scale was used to evaluate the quality of the selected studies, and meta-analysis was conducted using the CMA program. This review was registered at PROSPERO (CRD42018068633).

RESULTS: Of the total 13768 studies searched, 17 were selected. Positive effects on neck disability were achieved

$\dagger$ Corresponding Author : Han-Suk Lee leehansuk21@naver.com, http://orcid.org/0000-0002-9336-0894 This is an Open Access article distributed under the terms of the Creative Commons Attribution Non-Commercial License (http://creativecommons.org/licenses/by-nc/3.0) which permits unrestricted non-commercial use, distribution, and reproduction in any medium, provided the original work is properly cited. with the base and biomechanical elements ( $\mathrm{ES}=1.63,95 \%$ confidence interval [CI] .49 to 2.75 ) as well as base, modulator, and biomechanical elements $(\mathrm{ES}=1.50,95 \%[\mathrm{CI}]$ .69 to 2.30). Neck pain improved with the base, modulator, and biomechanical elements $(\mathrm{ES}=1.96,95 \%[\mathrm{CI}] 1.08$ to 2.82 ), while postural changes improved with biomechanical elements ( $\mathrm{ES}=1.45,95 \%[\mathrm{CI}] .64$ to 2.25 ). Additionally, type of exercise had a positive effect.

CONCLUSION: The most effective exercises for neck disability are of the base and biomechanical elements, while the most effective types for neck pain are of the base, modulator, and biomechanical elements and the most effective exercise for posture is of biomechanical elements. Combined exercises targeting biomechanical elements were effective at treating disability, pain, and postural changes.

Key Words: Exercise therapy, Meta-analysis, Posture

\section{Introduction}

Forward head posture, which is one of the most common neck disorders, is caused by sitting at a desk for extended periods (Good et al., 2001). Overall 30 to $50 \%$ of the annual workforce suffers from neck pain (Haldeman et al., 2010), 
and according to 2010 National Statistical Office data, the proportion of forward head posture induced by overuse of the internet increases with age, with a large proportion of those aged 15 to 50 years suffering from forward head posture (ICT, 2015).

Forward head posture is a state in which the position of the head is displaced anterior to the centerline of gravity (Salahzadeh et al., 2014), inducing instability in not only the cervical spine, but also the musculoskeletal system including the upper trunk (Griegel-Morris et al., 1992) and leading to chronic neck pain. Changes in posture caused by neck pain alter body balance control. During such changes, balance ability decreases, resulting in increased risk of falling and musculoskeletal injury. Accordingly, Lee et al. (2001) and Han et al. (2016) reported that forward head posture affects static equilibrium ability.

Meta-analysis is an efficient analytical scientific statistical method that can quantify and compare studies by effect size by analyzing quantitative research (Borenstein et al., 2009), and it can provide a very strong evidence (Oh, 2002). In addition, meta-analysis can enable limitations of sample size in individual studies to be overcome and generalized in clinical practice (Lee, 2007). Therefore, in the field of physical therapy, meta-analysis is used as a scientific analysis method to compare the effect of treatments.

In a study of meta-analysis related to neck pain, Gross et al. (2016) reported that exercise is effective at reducing neck pain symptoms and that strengthening exercise is moderately effective, but that the effects of endurance or stretching exercise were small. Similarly, Sihawong et al. (2011) reported that strengthening exercise and endurance exercise led to great reductions in neck pain, and Kay et al. (2005) reported that combined exercise had a large effect on reducing neck pain, but that, it was unclear whether exercise is more effective than electrotherapy or manual therapy. However, Geneen et al. (2017) reported that exercise and physical activity had a small effect on neck pain. Similarly, there are various causes of neck pain, and different effects are shown for various exercise. Therefore, it is necessary to analyze the causes of neck pain or disability.

Neck pain is affected by forward head posture, and neck dysfunction, forward head posture, and hyperkyphosis are related to each other (Lau et al., 2010). Bansal et al. (2014) reported that back muscle strengthening exercise had no effect on hyperkyphotic posture, but the average age in that study was more than 45 years old and subjects were biased. There is a wide range of age groups with forward head posture and there are many studies (Harman et al., 2005; Falla et al., 2007a; Lynch et al., 2010; Gupta et al., 2013) in which various types of exercise are applied to neck pain and posture enhancement, but there have been no analyses of various types of exercise. Consequently, it is necessary to analyze the effect of various types of exercise on forward head posture. Therefore, this study was conducted to analyze previous studies by including subjects of various ages with forward head posture, which is one of the causes of neck pain. Subjects with forward head posture suffer from pain and disability, which can be solved by exercise therapy; however, the most effective types of exercise need to be classified scientifically through meta-analyses. The specific research questions asked in this study were:

1. What type of exercise has the greatest effect on neck disability index (NDI) when applied to the forward head posture?

2. What type of exercise has the greatest effect on the visual analog scale (VAS)?

3. What type of exercise has the greatest effect on craniovertebral angle (CVA)?

\section{Method}

\section{Type of Study}

This study was a meta-analysis of Randomized controlled trials (RCTs) with systematic review. Therefore, 
this study was registered in the PROSPERO database (CRD42018068633) and conducted according to the recommendations of the PRISMA statement.

\section{Eligibility Criteria}

Studies that evaluated the effectiveness of exercise for subjects with forward head posture were included. The key data (PICO) was "what type of exercise (intervention) was better than conventional therapy (comparison) for improving disability, pain, posture (outcomes) of 15 to 50 year-old patients with forward head posture (participants)?".

We divided the intervention into four types based on previous studies (Sahrmann, 2002) for comparison of exercise types. The four exercise types were base element, modulator element, biomechanical element, and support element. Base element exercises target the functional status of the muscular and skeletal systems and are commonly linked to the biomechanical elements. This element provides the basics for extensibility and mobility, strengthening, and endurance. Modulator element exercise is related to motor control for neuromuscular re-education based on targeting of patterns and synchronization and proprioceptive input to the patient. Biomechanical element exercises consist of an interface between the motor control associated with a modulator and base element. Components of this element include static and dynamic stability. Support element exercise affect the functional status of the cardiac, pulmonary and metabolic systems consist of aerobic exercise (Gross et al., 2016).

\section{Study Selection and Data Sources}

Two independent researchers conducted searches of the domestic databases KISS, RISS and DBpia. In addition, the overseas databases PubMed, OVID, and Science Direct were used to search for articles published from 2007 to December 2017, with Korean and English as search languages. Search terms were retrieved using the AND / OR operator. The search terms included were forward

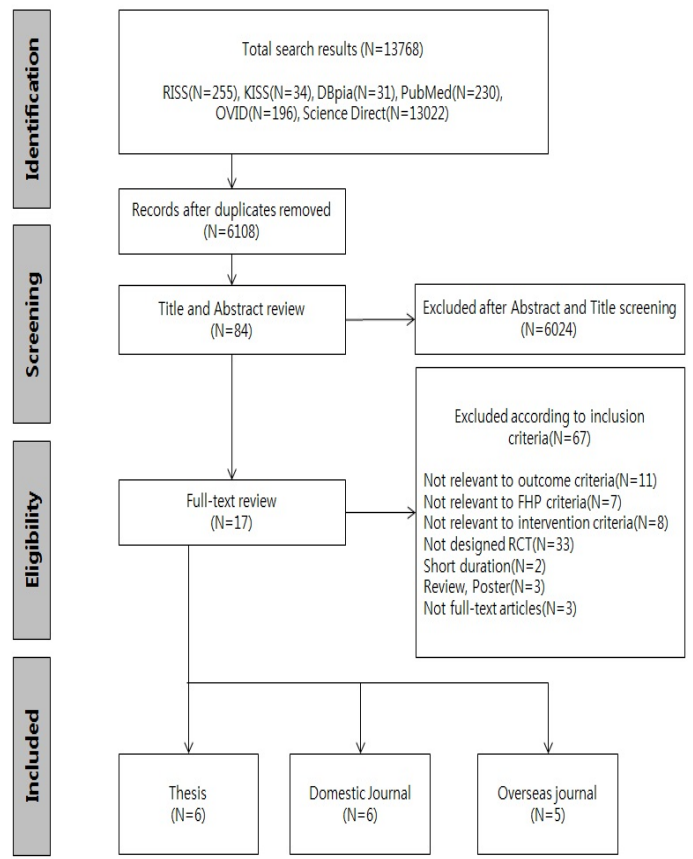

Fig. 1 Flow diagram of systematic review

head posture, electronic head posture, text head posture, and upper cross syndrome. The intervention search terms included were (exercise*) AND (rehabilitation* OR remed* OR therapy) OR exercise movement techniques (Larun et al., 2017). In the domestic database, search terms included words related to turtle neck, straight neck, anterior head posture, head forward displacement, exercise therapy, rehabilitation exercise, and exercise program. We excluded papers that had a study period less than 4 weeks, had unclear on the methods, were outside of the study age range, applied manual therapy to intervention, did not randomize treatments, or did not include appropriate outcome measures. Two researchers selected data through the key data (PICOS), study selection and exclusion criteria based on the retrieved data, and in the case of papers that were not agreed on, the selection of the papers was determined through consultation with a third party (Moher et al., 2009; Higgins and Green, 2011) (Fig. 1). 
Table 1. Characteristics of Study $(n=17)$.

\begin{tabular}{|c|c|c|c|c|c|c|}
\hline Study, year & Exercise description & Exercise type & Outcomes & Patients $(\mathrm{N})$ & Session weeks (min) & Weeks treatment \\
\hline Cha 2017 & $\begin{array}{l}\text { Neck flexion, Extension, } \\
\text { Shoulder flexion, Extension, } \\
\text { Horizontal adduction, Horizontal abduction, } \\
\text { External rotation, Internal rotation } \\
\text { stabilization Ex. used elastic band }\end{array}$ & $\begin{array}{l}\text { Biomechanical } \\
\text { Element: Stabilization Exercise }\end{array}$ & $\begin{array}{l}\text { NDI, VAS, } \\
\text { CVA, CRA, } \\
\text { Muscle thickness }\end{array}$ & 15 & $3(30)$ & 6 \\
\hline Choi 2007 & $\begin{array}{l}\text { Exercise program - Deep neck flexor, } \\
\text { Scapular retraction strengthening, Neck } \\
\text { extensor, Pectoralis stretching }\end{array}$ & $\begin{array}{l}\text { Base } \\
\text { Element: Strengthening exercise } \\
\text { and Stretching exercise }\end{array}$ & CVA, CRA & 8 & 4 & 10 \\
\hline Choi 2011 & $\begin{array}{l}\text { Exercise program - Deep neck flexor, } \\
\text { Scapular retraction strengthening, Neck } \\
\text { extensor, Pectoralis stretching }\end{array}$ & $\begin{array}{l}\text { Base } \\
\text { Element: Strengthening exercise } \\
\text { and Stretching exercise }\end{array}$ & CVA, CRA & 16 & 4 & 10 \\
\hline Diab 2011 & $\begin{array}{l}\text { Deep neck flexor, Shoulder retraction } \\
\text { strengthening, Neck extensor, } \\
\text { Pectoralis stretching }\end{array}$ & $\begin{array}{c}\text { Base } \\
\text { Element: Strengthening exercise } \\
\text { and Stretching exercise }\end{array}$ & $\begin{array}{l}\text { CVA, VAS, } \\
\text { Nerve root function }\end{array}$ & 48 & 3 & 10 \\
\hline Diab 2012 & $\begin{array}{l}\text { Deep neck flexor, Shoulder retraction } \\
\text { strengthening, Neck extensor, } \\
\text { Pectoralis stretching }\end{array}$ & $\begin{array}{l}\text { Base } \\
\text { Element: Strengthening exercise } \\
\text { and Stretching exercise }\end{array}$ & CVA, FRI & 38 & 3 & 10 \\
\hline Jang 2016 & $\begin{array}{c}\text { Sling Ex.-Relaxation, Sensorimotor, } \\
\text { Stabilizing Ex. For Neck } \\
\text { McKenzie Ex. - Sitting, Supine position } \\
\text { chin in, Neck extension, Neck side bending, } \\
\text { Neck rotation, Neck flexion stretching }\end{array}$ & $\begin{array}{c}\text { Base and } \\
\text { Modulator and } \\
\text { Biomechanical Element: } \\
\text { Combined Sling Exercise } \\
\text { Base } \\
\text { Element: McKenzie exercise }\end{array}$ & $\begin{array}{l}\text { VAS, NDI, } \\
\text { TPD, CVA }\end{array}$ & 15 & $3(20)$ & 6 \\
\hline Kang 2015 & $\begin{array}{l}\text { Craniocervical flexion used Pressure } \\
\text { Biofeedback Unit for Deep Neck flexor } \\
\text { strengthening }\end{array}$ & $\begin{array}{c}\text { Modulator } \\
\text { Element: Biofeedback }\end{array}$ & $\begin{array}{l}\text { CROM, CVA, } \\
\text { Muscle Endurance }\end{array}$ & 10 & $3(30)$ & 6 \\
\hline Kim 2011 & $\begin{array}{l}\text { Sling exercise-Neck flexor exercise, } \\
\text { Lower trapezius, Rhomboid, Serratus } \\
\text { anterior strengthening }\end{array}$ & $\begin{array}{c}\text { Base } \\
\text { Element: Sling exercise }\end{array}$ & $\begin{array}{c}\text { CVA, CRA, } \\
\text { Muscle activation, } \\
\text { Cervical Spine curvature }\end{array}$ & 12 & 2 & 4 \\
\hline Kim 2014 & $\begin{array}{l}\text { McKenzie Ex. - chin-in, Neck extension, } \\
\text { Side bending, rotation, flexion stretching, } \\
\text { Deep neck flexor strengthening }\end{array}$ & $\begin{array}{c}\text { Base } \\
\text { Element: McKenzie exercise }\end{array}$ & $\begin{array}{l}\text { Respiratory } \\
\text { function, CVA }\end{array}$ & 15 & $3(20)$ & 4 \\
\hline Kim 2016 & Oscillation Exercise with Body blade & $\begin{array}{l}\text { Biomechanical } \\
\text { Element: Body blade }\end{array}$ & $\begin{array}{l}\text { Muscle activation, } \\
\text { CVA, CRA }\end{array}$ & 12 & $3(60)$ & 6 \\
\hline Kim 2017 & $\begin{array}{c}\text { Shoulder stability exercise group - } \\
\text { Deep neck flexor, Green elastic } \\
\text { band retraction, Sling scapular setting, } \\
\text { Lower trapezius exercise } \\
\text { Thoracic extension exercise group } \\
\text { - Deep neck flexor, Foam roller thoracic } \\
\text { extension, Sling thoracic extension, } \\
\text { overhead squat }\end{array}$ & $\begin{array}{l}\text { Biomechanical } \\
\text { Element: Stabilization exercise }\end{array}$ & $\begin{array}{l}\text { NDI, CVA, } \\
\text { PPT, CRA, } \\
\text { Cervical } \\
\text { Lordosis angle }\end{array}$ & 10 & 3 & 8 \\
\hline Oh 2016 & $\begin{array}{l}\text { Neurofeedback brain training pottery game } \\
\text { and archery game using brain wave }\end{array}$ & $\begin{array}{c}\text { Modulator } \\
\text { Element: Neurobiofeedback }\end{array}$ & $\begin{array}{l}\text { NDI, CROM, } \\
\text { ARA, AWB }\end{array}$ & 20 & $3(12)$ & 4 \\
\hline Oh 2016-b & $\begin{array}{l}\text { PNF pattern flexion - Right lateral flexion } \\
\text { right rotation pattern, Extension } \\
\text { - Left flexion - Left rotation pattern }\end{array}$ & $\begin{array}{l}\text { Modulator } \\
\text { Element: PNF }\end{array}$ & $\begin{array}{l}\text { NDI, CROM, } \\
\text { ARA, AWB }\end{array}$ & 20 & $3(20)$ & 4 \\
\hline Ruvio 2016 & $\begin{array}{l}\text { Shoulder girdle, Deep neck flexor } \\
\text { strengthening, Neck, Pectoralis muscle } \\
\text { stretching }\end{array}$ & $\begin{array}{l}\text { Base } \\
\text { Element: Strengthening exercise } \\
\text { and Stretching exercise }\end{array}$ & $\begin{array}{l}\text { CVA, Sagittal head } \\
\text { tilt angle, Shoulder } \\
\text { angle, ASES }\end{array}$ & 42 & 2 & 32 \\
\hline Ruvio 2017 & $\begin{array}{l}\text { Shoulder girdle, Deep neck flexor } \\
\text { strengthening, Neck, Pectoralis muscle } \\
\text { stretching }\end{array}$ & $\begin{array}{c}\text { Base } \\
\text { Element: Strengthening exercise } \\
\text { and Stretching exercise }\end{array}$ & $\begin{array}{l}\text { CVA, Sagittal head } \\
\text { tilt angle, Shoulder } \\
\text { angle, ASES }\end{array}$ & 76 & 2 & 16 \\
\hline Shih 2017 & $\begin{array}{l}\text { Resisted isometric chin tuck in sitting } \\
\text { position and upper trunk extension with chin } \\
\text { tuck in prone }\end{array}$ & $\begin{array}{c}\text { Base } \\
\text { Element: Strengthening exercise }\end{array}$ & $\begin{array}{l}\text { NDI, CROM, } \\
\text { HFD, UCA, LCA }\end{array}$ & 20 & $2(30)$ & 5 \\
\hline Yoon 2014 & $\begin{array}{l}\text { Cervical exercise group - Forward, } \\
\text { Backward, Side, Rotation head press, } \\
\text { Supine, Prone, Side lying, } \\
\text { Prone rotation head hold, sit against } \\
\text { the wall Shoulder combine exercise group } \\
\text { - Add shoulder retraction and mobility, } \\
\text { Dynamic stability, Push-up plus exercise } \\
\text { at cervical exercise }\end{array}$ & $\begin{array}{c}\text { Base } \\
\text { Element: Strengthening exercise } \\
\text { Base and } \\
\text { Biomechanical Element: neck } \\
\text { and shoulder strengthening } \\
\text { and stabilization exercise }\end{array}$ & $\begin{array}{l}\mathrm{NDI} \text {, cobb angle, CGA, } \\
\text { Jackson angle, C2-7 } \\
\text { horizontal distance }\end{array}$ & 8 & $3(60)$ & 8 \\
\hline
\end{tabular}

\section{Risk of bias in individual studies}

The studies were evaluated for risk of bias by two independent reviewers using the PEDro scale (Maher et al., 2003). If there were disagreements, a third reviewer was consulted to make the final decision. According to PEDro items, two independent reviewers rated the score to evaluate the methodological quality of studies (Table 1). 
Table 2. Methodological Quality of Trials $(n=17)$

\begin{tabular}{|c|c|c|c|c|c|c|c|c|c|c|c|c|}
\hline Study & 1 & 2 & 3 & 4 & 5 & 6 & 7 & 8 & 9 & 10 & 11 & Score \\
\hline Cha 2017 & $\checkmark$ & $\checkmark$ & & $\checkmark$ & & & & $\checkmark$ & & $\checkmark$ & $\checkmark$ & 5 \\
\hline Choi 2007 & $\checkmark$ & $\checkmark$ & & $\checkmark$ & & & & $\checkmark$ & & $\checkmark$ & $\checkmark$ & 5 \\
\hline Choi 2011 & $\checkmark$ & $\checkmark$ & & $\checkmark$ & & & & $\checkmark$ & & $\checkmark$ & $\checkmark$ & 5 \\
\hline Diab 2011 & $\checkmark$ & $\checkmark$ & $\checkmark$ & $\checkmark$ & & & & $\checkmark$ & $\checkmark$ & $\checkmark$ & $\checkmark$ & 7 \\
\hline Diab 2012 & $\checkmark$ & $\checkmark$ & $\checkmark$ & $\checkmark$ & & & & $\checkmark$ & $\checkmark$ & $\checkmark$ & $\checkmark$ & 7 \\
\hline Jang 2016 & $\checkmark$ & $\checkmark$ & & $\checkmark$ & & & $\checkmark$ & $\checkmark$ & & $\checkmark$ & $\checkmark$ & 6 \\
\hline Kang 2015 & $\checkmark$ & $\checkmark$ & & $\checkmark$ & & & & $\checkmark$ & & $\checkmark$ & $\checkmark$ & 5 \\
\hline Kim 2011 & $\checkmark$ & $\checkmark$ & & $\checkmark$ & & & & $\checkmark$ & & $\checkmark$ & $\checkmark$ & 5 \\
\hline Kim 2014 & $\checkmark$ & $s$ & & $\checkmark$ & & & & $\checkmark$ & $\checkmark$ & & $\checkmark$ & 5 \\
\hline Kim 2016 & $\checkmark$ & $\checkmark$ & & $\checkmark$ & & & & $\checkmark$ & & $\checkmark$ & $\checkmark$ & 5 \\
\hline Kim 2017 & $\checkmark$ & $s$ & & $\checkmark$ & & & & $\checkmark$ & $\checkmark$ & $\checkmark$ & $\checkmark$ & 6 \\
\hline Oh 2016 & $\checkmark$ & $\checkmark$ & & $\checkmark$ & & & & $\checkmark$ & $\checkmark$ & $\checkmark$ & $\checkmark$ & 6 \\
\hline Oh 2016-b & $\checkmark$ & & & $\checkmark$ & & & & $\checkmark$ & $s$ & $\checkmark$ & $s$ & 5 \\
\hline Ruivo 2016 & $\checkmark$ & $\checkmark$ & $\checkmark$ & $\checkmark$ & & & $\checkmark$ & & & $\checkmark$ & $\checkmark$ & 6 \\
\hline Ruivo 2017 & $\checkmark$ & $\checkmark$ & $\checkmark$ & $\checkmark$ & & & $\checkmark$ & $\checkmark$ & & $\checkmark$ & $\checkmark$ & 7 \\
\hline Shih 2016 & $\checkmark$ & $\checkmark$ & $\checkmark$ & $\checkmark$ & & & $\checkmark$ & $\checkmark$ & $\checkmark$ & $\checkmark$ & $\checkmark$ & 8 \\
\hline Yoon 2014 & $\checkmark$ & $s$ & & $\checkmark$ & & & & $\checkmark$ & $\checkmark$ & $\checkmark$ & $\checkmark$ & 6 \\
\hline
\end{tabular}

PEDro items: 1 Eligibility criteria; 2 Random allocation; 3 Concealed allocation; 4 Comparability at baseline; 5 Patient blinding; 6 Therapist blinding; 7 Assessor blinding; 8 At least 85\% follow-up; 9 Intention to treat analysis; 10 Between-group statistical comparisons; 11 Point measures and measures of variability. Item 1 not included in PEDro score

\section{Summary measures}

The standardized mean difference (effect sizes) and 95\% CI were calculated based on preintervention means, postintervention means and standard deviations (SDs).

\section{Synthesis of results}

To compare the data analysis, the effect size was calculated using the CMA (Comprehensive Meta-Analysis, version 2.2.064, USA) software, and Cohen's criterion was used to analyze the effect size calculated as a result of the meta-analysis (Cohen, 1977). The random effect analysis was used depending on the results of homogeneous analysis.

\section{Results}

Of the 13,768 studies searched in domestic and overseas databases. 17 randomized controlled trials were selected. These included six domestic thesis, six domestic journal articles, and five overseas journal articles. A brief description of each research study is given in the research characteristics (Table 2).

\section{Homogeneity test}

The total number of research items analyzed in this study was 21 ( $\mathrm{Q}(21)=86.21, \mathrm{p}<.01)$, and a random effect model was used (Table 3 ). 
126 | J Korean Soc Phys Med Vol. 13, No. 3

Table 3. Homogeneity Test of Included Studies

\begin{tabular}{ccc}
\hline $\mathrm{K}$ & $\mathrm{Q}$ value & $\mathrm{p}$-value \\
\hline 21 & 86.21 & $.00^{*}$ \\
\hline
\end{tabular}

Table 4. Publication Bias of Included Studies (Trim and Fill)

\begin{tabular}{cccc}
\hline & Studies trimmed & ES & $95 \%$ CI \\
\hline Observed values & - & 1.06 & $.74-1.38$ \\
Adjusted values & 0 & 1.06 & $.74-1.38$ \\
\hline
\end{tabular}

ES=Effect size

Table 5. Effect Size of NDI and Homogeneity Test

\begin{tabular}{ccccccc}
\hline $\mathrm{K}$ & $\mathrm{ES}$ & $\mathrm{p}$-value & $95 \% \mathrm{CI}$ & $\mathrm{Q}$ value & $\mathrm{I}^{2}$ & $\mathrm{p}$-value \\
\hline 10 & .88 & $.00^{*}$ & $.63-1.13$ & 10.66 & 10.66 & .30 \\
\hline
\end{tabular}

Table 6. Effect Size by Each Intervention Type (NDI)

\begin{tabular}{ccccc}
\hline Treatment & K & ES & p-value & $95 \%$ CI \\
\hline BASE & 4 & .63 & $.00^{*}$ & $.25-1.03$ \\
BASE+BIO & 1 & 1.63 & $.01^{*}$ & $.49-2.75$ \\
BASE+MODULATOR+BIO & 1 & 1.50 & $.00^{*}$ & $.69-2.30$ \\
BIO & 2 & .99 & $.00^{*}$ & $.40-1.58$ \\
MODULATOR & 2 & .84 & $.00^{*}$ & $.36-1.30$ \\
\hline
\end{tabular}

$\mathrm{K}=$ Number of study, ES=Effect size, $\mathrm{SE}=$ standard error, $95 \% \mathrm{CI}=95 \%$ Confidence interval

\section{Publication bias}

Evaluation of publication bias examined according to Duval and Tweedie's trim and fill method (Duval and Tweedie, 2000) revealed that there was no publication bias (Table 4). There is no publication bias in the results of verifying additional publishing bias (Intercept $=2.32$, standard error $=1.32, \mathrm{p}=.09$ ).

\section{Effect size of NDI according to exercise type}

The total effect of 10 studies was investigated to establish the overall effect size of NDI, which was found to be large $(.88)$ and statistically significant $(\mathrm{p}<.05)$. The fixed-effect model was used because there was homogeneity between studies (Q $(10)=10.66, \mathrm{p}>.05$ ) (Table 5).

The largest effect size among the exercise types was for the combined base and biomechanical elements exercise
$(\mathrm{ES}=1.63,95 \%$ confidence interval $[\mathrm{CI}] .49$ to 2.75$)$ followed by the combination of base, modulator, and biomechanical elements ( $\mathrm{ES}=1.50,95 \%$ [CI] .69 to 2.30), biomechanical elements (ES=.99, 95\% [CI] .40 to 1.58), modulator elements $(\mathrm{ES}=.89,95 \%[\mathrm{CI}] .36$ to 1.30$)$, and then base elements (ES=.63, 95\% [CI] .25 to 1.03). All exercise showed statistically significant effect sizes $(p<.05)$ (Table 6).

4. The effect size of VAS according to exercise type

The total effects of the four studies were measured to establish the overall effect of VAS, and the effect size (.94) was found to be large and statistically significant $(p<.05)$. Therefore, the random effect model was used because there was heterogeneity between studies ( $Q$ 
Table 7. Effect Size of VAS and Homogeneity Test

\begin{tabular}{ccccccc}
\hline $\mathrm{K}$ & $\mathrm{ES}$ & $\mathrm{p}$-value & $95 \% \mathrm{CI}$ & $\mathrm{Q}$ value & $\mathrm{I}^{2}$ & $\mathrm{p}$-value \\
\hline 4 & .94 & $.00^{*}$ & $.30-1.50$ & 9.85 & 69.54 & $.02 *$ \\
\hline
\end{tabular}

Table 8 . Effect size by each intervention type (VAS)

\begin{tabular}{ccccc}
\hline Treatment & $\mathrm{K}$ & $\mathrm{ES}$ & $\mathrm{p}$-value & $95 \%$ CI \\
\hline BASE & 2 & .59 & $.00 *$ & $.23-.95$ \\
BASE+MODULATOR+BIO & 1 & 1.96 & $.00 *$ & $1.08-2.82$ \\
BIO & 1 & .48 & .19 & $-.24-1.20$ \\
\hline
\end{tabular}

$\mathrm{K}=$ Number of study, ES=Effect size, SE=standard error, $95 \% \mathrm{Cl}=95 \%$ Confidence interval

Table 9. Effect Size of CVA and Homogeneity test

\begin{tabular}{cccccccc}
\hline $\mathrm{K}$ & $\mathrm{ES}$ & $\mathrm{p}$-value & $95 \% \mathrm{CI}$ & $\mathrm{Q}$ value & $\mathrm{I}^{2}$ & $\mathrm{p}$-value \\
\hline 15 & 1.07 & $.00^{*}$ & $.86-1.20$ & 69.15 & 79.75 & .00 \\
\hline
\end{tabular}

Table 10. Effect Size by Each Intervention Type (CVA)

\begin{tabular}{ccccc}
\hline Treatment & K & ES & p-value & $95 \%$ CI \\
\hline BASE & 10 & .97 & $.00^{*}$ & $.79-1.16$ \\
BASE+MODULATOR+BIO & 1 & 1.45 & $.00^{*}$ & $.64-2.25$ \\
BIO & 3 & 1.77 & $.00^{*}$ & $1.21-2.34$ \\
MODULATOR & 1 & .14 & .76 & $-.74-1.01$ \\
\hline
\end{tabular}

$\mathrm{K}=$ Number of study, ES=Effect size, $\mathrm{SE}=$ standard error, $95 \% \mathrm{CI}=95 \%$ Confidence interval

(4)=9.85, p<.05) (Table 7).

The largest effect size among exercise types was that of the exercise type combining the base, modulator and biomechanical elements ( $\mathrm{ES}=1.96,95 \%$ [CI 1.08 to 2.82) followed by the base element $(\mathrm{ES}=.59,95 \%[\mathrm{CI}] .23$ to $.95)$, all of which were statistically significant $(\mathrm{p}<.05)$. Conversely, there were no significant differences among biomechanical elements $(\mathrm{ES}=.48,95 \%$ [CI] -.24 to 1.20$)$ (p>.05) (Table 8).

\section{Effect size of CVA according to exercise type}

The total effects of 15 studies were measured to establish the overall effects of CVA, and the effect size (1.07) was very large and statistically significant $(p<.05)$. The random effect model was used because there was heterogeneity between studies $(\mathrm{Q}(15)=69.15, \mathrm{p}<.01)$ (Table 9).

Among exercise types, the largest effect size was the biomechanical element (ES=1.77, 95\% [CI] 1.21 to 2.34), followed by the exercise type combining the base, modulator, biomechanical elements $(\mathrm{ES}=1.45,95 \%$ [CI] .64 to 2.25$)$, and base element $(\mathrm{ES}=.97,95 \%[\mathrm{CI}] .79$ to 1.16), all of which were statistically significant $(p<.05)$. Conversely, there were no significant differences in modulator elements $(\mathrm{ES}=.14,95 \%[\mathrm{CI}]-.74$ to 1.01$)(\mathrm{p}>.05)$ (Table 10).

\section{Discussion}

This study was conducted to examine the effects of different types of exercise on neck disability, neck pain, 
and neck posture. Methods for measuring neck disability in subjects with forward head posture or chronic neck pain were the NDI, the functional rating index, and the cervical range of motion. The methods used to measure neck pain were the VAS, a numerical pain-rating scale, and a pressure-pain threshold. The methods for evaluating neck posture were the CVA, cervical lordosis angle, three parameter distance, New York posture rating chart, and a head posture spine curvature instrument (Wilmarth and Hilliard, 2003). In this study, we used the NDI, VAS (Falla et al., 2007b; Akhter et al., 2014) and CVA (Wilmarth and Hilliard, 2003), which are commonly used to measure forward head posture. As a result, the most effective exercise type was combining the base and biomechanical elements for treating neck disorders. Combining the base, modulator, and biomechanical elements were the most effective exercise type for treating neck pain. For treating neck posture, the biomechanical element exercise type was most effective.

The quality of the studies was assessed using the PEDro scale, which had scores ranging from 5 to 8 . Only five studies (Diab 2011; Diab 2012; Ruivo 2016; Ruivo 2017; Shih 2016) had concealed allocation. Most studies did not blind the subjects or the therapist, but four studies (Jang 2016; Ruivo 2016; Ruivo 2017; Shih 2016) used assessor blinding. In domestic databases, no studies used concealed allocation, and use of assessor blinding was excluded (Jang 2016). Therefore, before analyzing the results of this study, it is necessary to consider the characteristics of the literature.

The results presented herein suggest that exercise improves neck disorders. The combination of base and biomechanical elements was found to be most effective. "Base element" refers to the base element of movement, which is the type of movement that provides muscular strength, endurance, mobility, length, and elasticity. "Biomechanical element" refers to the interaction between motor control and musculoskeletal function, which is a type of exercise that achieves static and dynamic stabilization (Sahrmann, 2002). In other words, in the case of neck disorders, NDI is believed to be improved because the biomechanical element has positive effects on neck and shoulder discomfort or function in daily life due to improvement of muscle strength, mobility, and stability of the neck and shoulder. The effect sizes of the other exercise types showed were very large, but the effect of base element on the NDI was moderate.

Unlike the present study, Gross et al. (2016) conducted a meta-analysis of the combined base and biomechanical exercise for chronic mechanical neck disorders and found that the effect size of neck function was moderate (-.45 (95\% [CI] -.72 to -.18)). Ferreira et al. (2006) conducted a meta-analysis of the effects of specific stabilization exercises on the spine and pelvis and found that the effects of biomechanical type of exercise were greater than those of manual therapy on a $0-100$ scale to $-7(95 \%$ [CI] -13 to -2 ). The results of this study differ from those of previous studies because of differences in the subjects, which seems to be the result of analysis of various conditions, such as chronic mechanical disorders. In addition, the application of biomechanical element exercise seems to be more effective at resolving the neck posture of subjects with forward head posture, resulting in less abnormal stress because of improper posture, reduction of muscle length, recovery of unbalanced muscle strength, and postural alignment stability. The effect size of exercise combining base, modulator, and biomechanical elements was 1.50 (95\% [CI] .69 to 2.30), which was less effective than that of exercise combining basic and biomechanical elements. This seems to be because of differences in exercise time.

In this study, neck pain (VAS) was found to be improved by exercise intervention. When analyzed by exercise type, treatment with a combination of base, modulator, and biomechanical elements proved was most effective. The modulator element is a type of exercise that regulates motor control or retrains the nerve roots through pattern, 
synchronization, and proprioceptive sensory input (Sahrmann, 2002). Alterations in movement strategy and postural activity because of proprioceptive sensory changing affect musculoskeletal pain syndrome (Matre et al., 2002). In other words, improving the regulatory function of the nervous system by enhancing muscle strength, mobility, and stability as well as proprioceptive sensory or motor control seems to be effective at improving neck pain.

Similar to this study, Gross et al. (2016) found that the effect size of neck pain was moderate in the results of a meta-analysis of exercise for chronic mechanical neck disorders by combining base, modulator, and biomechanical elements on the neck and shoulder. Cramer et al. (2017) found that the effect size was $-1.28(95 \%$ [CI] -1.81 to -.75 ) when using the base element for neck pain as a result of a meta-analysis of the effects of yoga on chronic neck pain. In this study, the effect size of exercise combined with base, modulator, and biomechanical elements was 1.96 (95\% [CI 1.08 to 2.82$)$, which was a very large. Additionally, the effect size was .59 (95\% [CI] .23 to .95) when only the base element was applied. The results of this study showed that when the base element and the biomechanical element were applied alone, the effect size was moderate or statistically insignificant, but that it was very large when the exercise was combined with the basic, modulator and biomechanical elements. These results were consistent with those of previous studies (Kay et al., 2005) in which complex exercise was effective at reducing neck pain, indicating that application of the complex motion type is more effective than application of a single motion type because the neck pain of a subject with a forward head posture is caused by reduction in muscle length in response to abnormal stress caused by an incomplete posture or by an imbalance of muscle strength, which also affects motor control in a complex way (Hickey et al., 2000).

The results of this study also suggest that exercise improves neck posture (CVA). When analyzed by exercise type, the biomechanical element was most effective, and exercise types that combined the base, modulator, and biomechanical elements were also very effective.

Forward head posture leads to body mechanical deformation anterior to the centerline of gravity, reduces muscle strength of the neck stabilization muscles, reduces the activity of the stabilizer muscles of the scapulae (Thigpen et al., 2010) and changes the body mechanics of the scapulae. Stimulation of the weakened stabilized muscles can make the posture of the head closer to normal by adjusting the posture (Im et al., 2015). Therefore, posture alignment exercise related to stability seems to have a positive effect on neck posture because of improvement of deep stabilization and stimulation of weakened stabilizer muscles. There was no specific meta-analysis of forward head posture. Bansal et al. (2014) conducted a systematic review of the effects of exercise on posture improvement of thoracic kyphosis associated with forward head posture and found that back extensor strengthening, which is a base element was not effective at improving posture. (Lau et al., 2010) However, this study showed that there was large effect of the base element on forward head posture of $.97(95 \%[\mathrm{CI}] .79$ to 1.16). One potential reason for these opposing findings is that the subjects were 45 years of age or older in the previous study and degenerative diseases related to hyperkyphosis are associated with age. Exercise types that have a positive effect on neck posture showed that a single exercise is more effective than a combined exercise. In the present study, the effect seemed to be larger because the application time of a single exercise is longer than the application time of a combined exercise.

The results of this study showed that exercise was most effective when combined with biomechanical elements for neck disability, pain, and posture in the forward head posture. This suggests that pain and disability are increased because of incomplete alignment of the head posture (Yip et al., 2008), which can be solved by restoration of the 
neck posture when the exercise type of the biomechanical element, which is the movement combined with the posture stability, is applied. Two combined or a single exercise were more effective than three combinations for treatment of neck disability or neck posture. This is because the exercise time associated with two combined or a single exercise is longer than that of the three combined exercises. The difference in exercise time seems to have affected the impact of exercise type on neck disability and neck posture.

The limitations of this study include the small number of studies used for the analysis. The reason for the low number of studies is that non-randomized control group studies comparing the effects of exercise therapy without control groups were common in domestic papers, and the experimental period was frequently less than 4 weeks. In overseas papers, there were more studies on chronic neck pain than forward head posture, and the number of articles meeting the selection criteria was very small. In this study, it is difficult to make definite conclusions about neck disability, pain and neck postures based on forward head posture. Most of the studies did not mention the random allocation or concealed allocation, which could affect the quality of the study. Moreover, most studies were not performed with investigators or participants blinded to treatment conditions. In addition, only the three combined exercise types (base, modulator, and biomechanical elements) were analyzed, and studies using the combined exercise of two types were lacking. We suggest that a multidisciplinary study with a high quality of research be conducted to identify effective methods of treatment of forward head posture and the effects of combination of these treatments

\section{Conclusion}

The results of this study showed that the most effective exercise type for neck disability with forward head posture was exercise with base and biomechanical elements and that the most effective exercise type for neck pain is exercises targeting base, modulator, and biomechanical elements. Finally, the most effective exercise type for neck posture CVA appeared to be those targeting only the biomechanical elements.

\section{References}

Akhter S, Khan M, Ali SS, et al. Role of manual therapy with exercise regime versus exercise regime alone in the management of non-specific chronic neck pain. Pak J Pharm Sci. 2014;27(6):2125-8.

Bansal S, Katzman WB, Giangregorio LM. Exercise for improving age-related hyperkyphotic posture: a systematic review. Archives of physical medicine and rehabilitation. 2014;95(1):129-40.

Borenstein M, Hedges L, Higgins J, et al. Introduction to Meta-Analysis John Wiley \& Sons. Ltd, Chichester, UK. 2009.

Cohen J. Statistical power analysis for the behavioral sciences: 1st Editon. Academic press: New York. 1977.

Cramer H, Klose P, Brinkhaus B, et al. Effects of yoga on chronic neck pain: a systematic review and meta-analysis. Clinical rehabilitation. 2017;31(11): $1457-65$.

Duval S, Tweedie R. Trim and fill: a simple funnelplot-based method of testing and adjusting for publication bias in meta-analysis. Biometrics. 2000;56(2):455-63.

Falla D, Jull G, Russell T, et al. Effect of neck exercise on sitting posture in patients with chronic neck pain. Phys Ther. 2007b;87(4):408-17.

Falla D, Jull G, Russell T, et al. Effect of neck exercise on sitting posture in patients with chronic neck pain. Physical therapy. 2007a;87(4):408-17.

Ferreira PH, Ferreira ML, Maher CG, et al. Specific stabilisation exercise for spinal and pelvic pain: a systematic review. Journal of Physiotherapy. 2006;52(2):79-88. 
Geneen LJ, Moore A, Clarke C, et al. Physical activity and exercise for chronic pain in adults: an overview of Cochrane Reviews. The Cochrane database of systematic reviews. 2017.

Good M, Stiller C, Zauszniewski JA, et al. Sensation and distress of pain scales: reliability, validity, and sensitivity. Journal of nursing measurement. 2001; 9(3):219-38

Griegel-Morris P, Larson K, Mueller-Klaus K, et al. Incidence of common postural abnormalities in the cervical, shoulder, and thoracic regions and their association with pain in two age groups of healthy subjects. Physical therapy. 1992;72(6):425-31.

Gross A, Paquin J, Dupont G, et al. Exercises for mechanical neck disorders: A Cochrane review update. Manual therapy. 2016;(24):25-45.

Gupta BD, Aggarwal S, Gupta B, et al. Effect of deep cervical flexor training vs. conventional isometric training on forward head posture, pain, neck disability index in dentists suffering from chronic neck pain. Journal of clinical and diagnostic research: JCDR. 2013; 7(10):2261-4.

Haldeman S, Carroll L, Cassidy JD. Findings from the bone and joint decade 2000 to 2010 task force on neck pain and its associated disorders. Journal of occupational and environmental medicine. 2010; 52(4):424-7.

Han JH, Kim JH, Jeong MG, et al. Correlation between forward head posture and foot pressure according to McKenzie exercise. Korean journal of orthopedic manual therapy. 2016;22(1):65-70.

Harman K, Hubley-Kozey CL, Butler H. Effectiveness of an exercise program to improve forward head posture in normal adults: a randomized, controlled 10-week trial. Journal of Manual \& Manipulative Therapy. 2005;13(3):163-76.

Hickey ER, Rondeau MJ, Corrente JR, et al. Reliability of the cervical range of motion (CROM) device and plumb-line techniques in measuring resting head posture (RHP). Journal of Manual \& Manipulative Therapy. 2000;8(1):10-7.

Higgins JP, Green S. Cochrane handbook for systematic reviews of interventions. John Wiley \& Sons. 2011.

ICT MoSa : Health problems due to overuse of the internet, 2010. Korea National Statistical Office 2015 http://kostat.go.kr. March 13, 2017.

Im B, Kim Y, Chung Y, et al. Effects of scapular stabilization exercise on neck posture and muscle activation in individuals with neck pain and forward head posture. Journal of physical therapy science. 2015;28(3):951-5

Kay TM, Gross A, Goldsmith C, et al. Exercises for mechanical neck disorders. Cochrane Database Syst Rev. 2005;3(3):1-105.

Larun L, Brurberg KG, Odgaard-Jensen J, et al. Exercise therapy for chronic fatigue syndrome. Cochrane Database Syst Rev. 2017;23(3):144.

Lau KT, Cheung KY, Chan MH, et al. Relationships between sagittal postures of thoracic and cervical spine, presence of neck pain, neck pain severity and disability. Manual therapy. 2010;15(5):457-62.

Lee CH. Research Methodology for Physical Therapists and Occupational Therapists 3rd Edition. Seoul: GYECHUK MUNWHASA. 2007.

Lee C-M, Jeong E-H, Freivalds A. Biomechanical effects of wearing high-heeled shoes. International journal of industrial ergonomics. 2001;28(6):321-6.

Lynch SS, Thigpen CA, Mihalik JP, et al. The effects of an exercise intervention on forward head and rounded shoulder postures in elite swimmers. Br J Sports Med. 2010;44(5):376-81.

Maher CS, Christopher G, Robert D Herbert, et al. Reliability of the PEDro Scale for Rating Quality of Randomized Controlled Trials. Physical Therapy. 2003;83(8): 713-21.

Matre D, Arendt-Nielsen L, Knardahl S. Effects of localization and intensity of experimental muscle pain on ankle 
joint proprioception. European Journal of Pain. 2002;6(4):245-60

Moher D, Liberati A, Tetzlaff J, et al. Preferred reporting items for systematic reviews and meta-analyses: the PRISMA statement. BMJ. 2009;6(7):1-6

Oh SS. Theory and Practice of Meta-Analysis. Seoul: Konkuk University Press. 2002.

Sahrmann S. Diagnosis and treatment of movement impairment syndromes. Elsevier Health Sciences. 2002.

Salahzadeh Z, Maroufi N, Ahmadi A, et al. Assessment of forward head posture in females: observational and photogrammetry methods. J Back Musculoskelet Rehabil. 2014;27(2):131-9.
Sihawong R, Janwantanakul P, Sitthipornvorakul E, et al. Exercise therapy for office workers with nonspecific neck pain: a systematic review. Journal of Manipulative \& Physiological Therapeutics. 2011;34(1):62-71.

Thigpen CA, Padua DA, Michener LA, et al. Head and shoulder posture affect scapular mechanics and muscle activity in overhead tasks. Journal of Electromyography and kinesiology. 2010;20(4):701-9.

Wilmarth M, Hilliard T. Measuring head posture via the craniovertebral angle. Orthopaedic Physical Therapy Practice. 2003;14(1):13-5.

Yip CHT, Chiu TTW, Poon ATK. The relationship between head posture and severity and disability of patients with neck pain. Manual therapy. 2008;13(2):148-54. 